\section{A STUDY OF DIABETES}

\section{Diabetes in an English Community}

A Study of Its Increase and Natural History. By Joan B. Walker and David Kerridge. Pp. 46. (Leicester: The University Pross, 1961.) 7s. 6d.

A VALUABLE survey of the incidence and natural history of diabetes in a rural parish (Ibstock in Leicestershire) has been made by Dr. Joan Walker of Leicester Royal Infirmary and David Kerridge of the University of Sheffield.

The inquiry was initiated in 1955 by the British Diabetic Association in an attempt to arrive at a numerical evaluation of the problem of diabetes in Britain. The figures available from the General Register Office vary from two to four diabetics per thousand of the population, but these figures refer to known diabetics. It was well known from the United States and Canada that, in previous surveys, as many unknown diabetics were found as those already diagnosed.

Many of the methods used by other investigators depended on the study of clinics, schools, factories, prisons and other such institutions, which are special groups with age and sex selection, while detection drives, although not restricted to special age or occupation groups, depend on voluntary initiative and tend to have low response-rates, and therefore allow too much room for bias. Throughout the year 1956, these ways of determining the incidence of diabetes in Britain were discussed. It was essential to find a method which would be practical, easily applied elsewhere, and be, at the same time, accurate. It was agreed that no census of known diabetics attending clinies could produce the information required. As it was most important for the purposes of the investigation that follow up should be possible, it was finally decided to investigate a compact stable community.

Because the diabetic clinic at Leicester Royal Infirmary served the City and whole County of Leicestershire, and because some of the Leicestershire villages had exceptionally static populations, it was decided to investigate a village community with the view of its becoming part of any larger national or international survey which might be undertaken later.

The objectives of the inquiry were as follows: to establish the number of diabetics in a natural area where the population is static, to discover the undiagnosed cases of diabetes, to investigate the possible hereditary factors; to investigate the possible æetiological factors of physique, diet habits, stress, occupation, and parity in women; to follow up the cases of glycosuria discovered by the investigation, if possible, for as long as twenty years, and to watch for new cases developing in the area; to repeat the whole survey at a future date and to repeat it also in another area of England for comparison or contrast.

Every person living in the village who was over the age of five years was asked to supply a specimen of urine and to answer a questionnaire. Altogether 2,071 males and 2,034 females were tested making an 81 per cent response of the population over the age of five years. Details of thirty-three previously diagnosed cases were collected from general practitioners' and clinic records. So far as could be determined the 19 per cent of non-co-operators were not different in age or other environmental factors from the rest, and in calculating rates, it was assumed that they were a random sample of the whole population.

The results show that there are about thirteen diabetics per thousand of the population, half of whom are asymptomatic. The relationship of diabetes to various social factors was examined. Plans for a follow-up study of the population are also described in the booklet.

\section{ANALYTICAL INSTRUMENTATION}

Physical Methods in Chemical Analysis

Vol. 1. Edited by Walter G. Berl. Second Edition. Pp. xiv +686. (New York: Academic Press Inc.; London: Academic Press Inc. (London), Ltd., 1960.) 19 dollars.

A DVANCES and refinements in analytical instruA mentation must, of necessity, call for periodic reviews of those publications which form such an essential part of that ever-expanding physicochemical noosphere from which the modern scientist draws both inspiration and knowledge. This present revision (Volume 1) of a well-known authoritative treatise on instrumental methods in chemical analysis belongs to this category.

The more elementary student may find the advanced and detailed form of presentation somewhat bewildering, but as his knowledge increases and he joins the ranks of the experts, he will undoubtedly appreciate the lucidity with which the various specialist contributors have described those practical and theoretical problems which are concomitant with the complex field of contemporaneous instrumentation. This is, however, a book which has been written by experts for experts, and, at the academic stage, it will undoubtedly be of the greatest assistance to honours graduates and research workers. Most modern instrumental methods are described with much attention to practical laboratory detail. Nearly a quarter of the 670-page work is devoted to X-ray diffraction techniques as applied to powders, metals and polymeric fibres. Spectrophotometry, emission spectrography and infra-red spectroscopy are given comprehensive treatment in chapters of about 80 pages each. The diagrammatic illustrations are clear and well annotated and each chapter concludes with an extensive bibliographical reference section.

Later sections deal with Raman spectra, measurements of refractive index, mass spectrometry, and electron microscopy and diffraction. The latter technique is particularly valuable for those crystallographic investigations on surfaces where the affected layer is too thin to be detected by $\mathrm{X}$-rays. The section on electron microseopy gives some extremely interesting reproduetions of electron micrographs of films of various materials.

The applications and design of simple and tandem mass spectrometers are described in some detail. Reference is made to the usages of such instruments in the analysis of chemical mixtures, the leak-testing of evacuated vessels, measurements of appearance potentials and related thermal quantities, reaction kinetic studies, etc.

This new edition undoubtedly provides up-to-date information on progress in the development and application of physical instrumentation and will be eagerly acquired by all chemists having an interest in the theory and practice of these specialized analyti. cal techniques.
D. T. Lewrs 